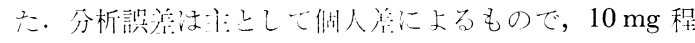
度すニオブ（V）に対して $\pm 0.3 \%$ 以内である。

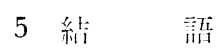

位来ふ劣り裬雑であのたチタン，ジルコニウム共存系

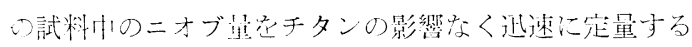
ケ法至見いだした。この方泛注非常に簡易な操作だけで

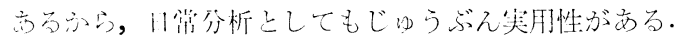

本研筷に対しご解可ごベえたつを賜わった松下電器産

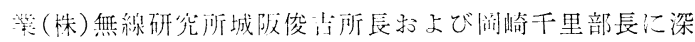
く感謝し安吋。

\section{交献}

1）日本分析化学会䌮：“分析化学講座”, 10-B（重 量分析 II)，p. 140 (1957)，(共立出版).

2) 日本分析化学会編 : “新分析化学講座”, 7 (容量 分所の忘用), p.77 (1957), (共立出版).

3) F. C. Palilla, N. Adler, C. F. Hiskey : Anal. Chem., 25, 926 (1953).

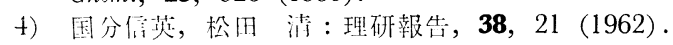

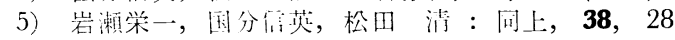
(1962).

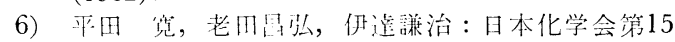
牛会講演要旨集，p. 340 (1962).

Rapid volumetric determination of niobium in the presence of titanium and zirconium by hydrogen peroxide complex formation. Toshioki
Amemiya and Hiroshi Hirata (Wireless Research Laboratory, Matsushita Electric Industrial Co., Ltd., Kadoma, Kadoma-shi, Osaka-fu)

Complexes of titanium and niobium with hydrogen peroxide are similarly formed in a dilute sulfuric acid solution, but their reactivities with potassium permanganate are distinctly different from each other against the concentration of sulfuric acid. Titaniumhydrogen peroxide complex readily reacts with potassium permanganate. Niobium complex $\left(\mathrm{Nb}: \mathrm{H}_{2} \mathrm{O}_{2}=\right.$ $1: 1)$ does not react in the sulfuric acid concentration less than $3 M$, but does completely in that more than $8 \mathrm{M}$. On the other hand, no complex of zirconium is formed with hydrogen peroxide.

The recommended procedure for determination of niobium is as follows. One gram of sample (mixture of oxides of titanium, niobium and zirconium) is heated to dissolve in the mixture of $5 \mathrm{ml}$ of $98 \%$ sulfuric acid and $3 \mathrm{~g}$ of ammonium sulfate, and diluted to $100 \mathrm{ml}$ with distilled water. An aliquot of this solution is mixed with $5 \mathrm{~m} l$ of $0.1 M$ hydrogen peroxide, and titrated with $0.04 M$ potassium permanganate solution. The amount of niobium is calculated from the difference of the added and titrated volumes of hydrogen peroxide. To the above titrated solution is then added gradually the same volume of $98 \%$ sulfuric acid in an ice-water bath, and the titration is carried out at below $20^{\circ} \mathrm{C}$. The amount of niobium is also calculated from this titer. One $\mathrm{ml}$ of $0.04 M \mathrm{KMnO}_{4}$ corresponds to $9.29 \mathrm{mg}$ of niobium.

A number of samples can be analyzed by the proposed method rapidly and conveniently without any special equipment or chemicals.

(Received Oct. 12, 1967)

\title{
フィチンによる金属イオンの沈殿 分離*
}

\author{
二村 英治，黒木 弘**
}

\footnotetext{
フィチン老历いて金属イオンを沈殿分離し，これを鉄鋼分析に利用する目的で基礎実験を行なった： 兴の絬果，次のことが闭らかとなった。(1) フィチンにより希酸性溶液から沈殿する金属イオンはチ夕 ン (IV)，ジルコニウム (IV)，ニオブ (V)，タンタル (V)，スズ (IV) およびトリウム (IV) であ る.（2）二机らの回収率法過塩素酸酸性が最もよく，ついで硫酸，塩酸の順である。(3) 鉄 (II) の共

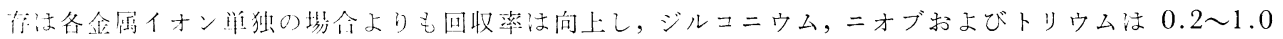
$N$ の冬利の邽性溶液から $100 \%$ 沈殿するが，チタン，スズおよびタンタルは過塩素酸酸性溶液のほか 沈不宽全であった。（4）卻（III）は，沈殿の生成を妨害与る。
} 


\section{1 緒言}

メソーイノシットのヘキサリン酸エステルであるフィ チン酸 $\left(\mathrm{C}_{6} \mathrm{H}_{18} \mathrm{O}_{24} \mathrm{P}_{6} \cdot 3 \mathrm{H}_{2} \mathrm{O}\right)$ およびそのカルシウム・マ グネシウム塩であるフィチンは分析試薬としてはほとえ ぞ知られていず，わずかに Sandell の著書1にスカンジ ウムと難溶性塩をつくることが記されているのタであ る、著者らはたまたまフィチンがチタンと希酸性溶液か ら沈殿することに着目し，フィチンの金属イオン沈殿郕 としての性質および種々の金属イオンとの沈殿反応につ いて調ベた。

\section{2 試薬および装置}

\section{$2 \cdot 1$ 試 薬}

フィチン溶液（1 w/v\%，1 $N$ 塩酸，過塩素酸または 硫酸酸性）：特級フィチン酸カルシウム $1 \mathrm{~g}$ に $1 N$ の塩 酸，過塩素酸または硫酸 $100 \mathrm{ml}$ を加え，加温して溶解 し，不溶解物をろ過して用いた。

標準金属溶液：純良な金属または金属塩を使用し，各 金属イオンの濃度は鉄以外はいずれも $1 \mathrm{mg} / \mathrm{ml}$ とした。

\section{$2 \cdot 2$ 装}

吸光度の測定には日立製作所製 EPU-2A 形光電分光 光度計，または東京光電製 $7 \mathrm{~B}$ 形光電光度計を使用し た。

\section{3 実験および結果}

\section{1 フィチンと金属イオンとの沈殿反応の定性試験}

主之して鉄鋼中に共存する鍂属元素，また添添加它予 想される金属元素の計 27 元素について，それぞれ塩酸， 過塩素酸および硫酸の約 $0.5 N$ 溶液からフィチンによる 沈殿生成状態を定性的に調ベた。

各標準金属溶液 $2 \mathrm{ml}$ をビーカー（容量 $300 \mathrm{ml}$ ) に とり，塩酸，過塩素酸および硫酸をと扎でれ最終液量 (約 $200 \mathrm{ml}$ ) において酸濃度が約 $0.5 N$ になるように し，液量を約 $200 \mathrm{~m} l$ とし，こ机にフィチンの各種酸性 溶液（試料溶液が塭酸酸性の場合注酸酸性のフィチン 溶液，過塩素酸酸性の場合法過塩素酸酸性のフィチン溶 液）を $10 \mathrm{ml}$ 加えてかき混ぜ，加熱して 10 ～15 分間堂 沸したのち熱源から降ろし，約 30 分間静置したのち沈 殿の生成状態を観察した。

その結果，Table I に示寺ように，添加金属イオンの うちチタン (IV)，ジルコニウム (IV)，ニオブ (V)， タンタル $(\mathrm{V}) ，$ スズ (IV) 尔よびトリウム (IV) の6 種の金属イオンが，塩酸，過塩素酸および硫酸の各希酸 性溶液から白色コロイド状の沈殿を生成した。ただし塩
酸酸性溶液ではスズ（IV)，タンタル（V) 注わ゙ふに 沈殿を認めた程度であった。なお沋殿した元絭の活とえ どが周期率表の第 4 属沶よび第 5 属に属しているのた， 上記 6 元素以外にジルコニウムと化学的性買の類似して いるハフニウムも沈殿を生成するものと思打机るが，今 回はハフニウムについては笑験しなからた。

Table I Qualitative reactions of metal ions with phytin

\begin{tabular}{|c|c|c|c|}
\hline \multirow{2}{*}{ Ion } & \multicolumn{3}{|c|}{ Formation of precipitate } \\
\hline & From $\mathrm{HCl}$ soln. & From $\mathrm{HClO}_{4}$ soln. & From $\mathrm{H}_{2} \mathrm{SO}_{4}$ soln. \\
\hline $\mathrm{Be}^{2+}$ & $x$ & $x$ & $x$ \\
\hline $\mathrm{Al}^{3+}$ & $x$ & $x$ & $x$ \\
\hline $\mathrm{Ti}^{4+}$ & 0 & 0 & 0 \\
\hline $\mathrm{V}^{4+}$ & $x$ & $x$ & $x$ \\
\hline $\mathrm{Cr}^{3+}$ & $x$ & $x$ & $x$ \\
\hline $\mathrm{Mn}^{2+}$ & $\times$ & $x$ & $x$ \\
\hline $\mathrm{Fe}^{2+}$ & $\triangle$ & $\therefore$ & $\therefore$ \\
\hline $\mathrm{Co}^{2+}$ & $x$ & $x$ & $\times$ \\
\hline $\mathrm{Ni}^{2+}$ & $x$ & $x$ & $x$ \\
\hline $\mathrm{Cu}^{2+}$ & $x$ & $x$ & $x$ \\
\hline $\mathrm{Zn}^{2+}$ & $x$ & $x$ & $x$ \\
\hline $\mathrm{Ge}^{4+}$ & $x$ & $x$ & $x$ \\
\hline $\mathrm{AsO}_{3}{ }^{3-}$ & $x$ & $\mathrm{x}$ & $x$ \\
\hline $\mathrm{Y}^{3+}$ & $\times$ & $\times$ & $x$ \\
\hline $\mathrm{Zr}^{4+}$ & 0 & 0 & 0 \\
\hline $\mathrm{Nb}^{5+}$ & 0 & 0 & 0 \\
\hline $\mathrm{Mo}^{5+}$ & $x$ & $x$ & $\times$ \\
\hline $\mathrm{Sn}^{4+}$ & $\triangle$ & 0 & 0 \\
\hline $\mathrm{Sb}^{3+}$ & $x$ & $x$ & $x$ \\
\hline $\mathrm{La}^{3+}$ & $x$ & $x$ & $\times$ \\
\hline $\mathrm{Ce}^{4+}$ & $x$ & $x$ & $x$ \\
\hline $\mathrm{Ta}^{5+}$ & $\triangle$ & 0 & 0 \\
\hline $\mathrm{WO}_{4}{ }^{2-}$ & $x$ & $x$ & $x$ \\
\hline $\mathrm{Pb}^{2+}$ & $x$ & $\times$ & $x$ \\
\hline $\mathrm{Bi}^{2+}$ & $\times$ & $x$ & $\times$ \\
\hline $\mathrm{Th}^{4+}$ & 0 & 0 & 0 \\
\hline $\mathrm{UO}_{2}{ }^{2+}$ & $\times$ & $x$ & $x$ \\
\hline
\end{tabular}

\section{2 沈殿生成条件の検討}

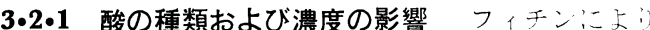
沈殿を生成したチタン (IV)，ジルコニウム (IV)，二 オブ $(\mathrm{V})$ ，タンタル $(\mathrm{V})$ ， スズ (IV) およびトリウム

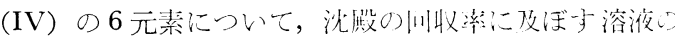

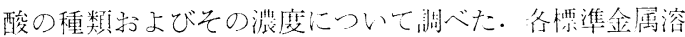

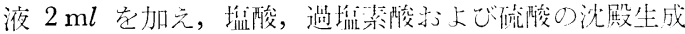
時の搌度を $0.2 〜 1.0 \mathrm{~N}$ に劣化してフィチンによっ沈殿

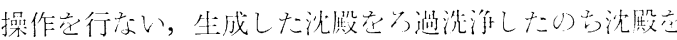
溶解してチタンは過凌化水采江，ジルコニウム㳉キシレ ノールオレンジ法，二オブおよびタンタルはピリジルア 


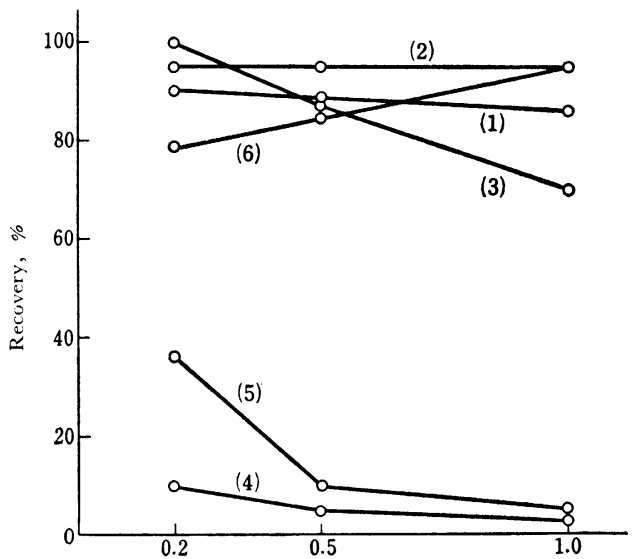

Hydrochloric acid concentration, $N$
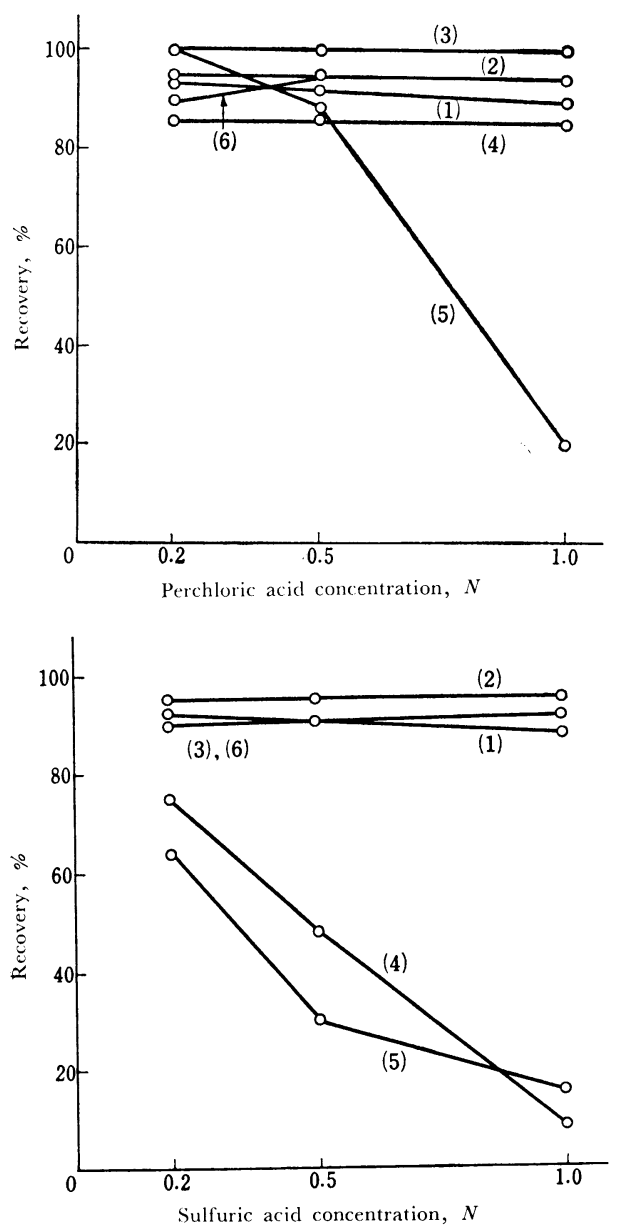

Fig. 1 Effect of concentration of hydrochloric, perchloric or sulfuric acid on the precipitation of metal ions

(1) Titanium; (2) Zirconium; (3) Niobium;

( 4 ) Tantalum; (5) Tin; (6) Thorium
ゾレゾルシノール法, スズはピロカテコールバイオレッ ト法，トリウムはアルセナゾ III 法などの吸光光度法で それぞれ定量し，その值から各金属イオンの回収率を求 わた. その結果を Fig.1 に示す.なお予備実験の結果， 鉄 (III) の共存は各金属イオンの回収率をかなり低下与 ることが認められたので，硝酸酸性については実験しな かった。

Fig. 1 に示すように, 過塩素酸酸性溶液が最も回収率 が高く，ついで硫酸および塩酸の順であった. 酸の濃度 の影響については，0.2〜1.0N の範囲ではチタン，二 オブ，タンタル，スズは希薄なほうが回収率がよく，ジ ルコニウムおよびトリウムはその逆であった.

3.2.2 鉄の影響 次に鉄鋼試料に適用するため鉄の 影響を調べた。

(1) 第一鉄イオン: 各標準金属溶液 $2 \mathrm{~m} l$ に鉄 (II) $1 \mathrm{~g}$ を含毛溶液を加え， $3 \cdot 2 \cdot 1$ と同様に酸の種類および 濃度を变えて各金属イオンの回収率を調べた。その結 果，Fig. 2 に示すように，酸の種類および濃度の影響 は，Fig.1 に示した各金属イオン単独の場合とほぼ同症 であったが，回收率沈い゙れも単独の場合よりもかなり よくなることがわかった. ジルコニウム，ニオブおよび トリウムは塩酸, 過塩素酸, 硫酸いずれの酸性溶液から も100\% 沈殿するのに対し，チタン，タンタル，スズは 過塩素酸酸性溶液以外では不完全であった。

（2）第二鉄イオン：鉄（III） $1 \mathrm{~g}$ 共存の場合注，各 金属イオンともその回收率は鉄（II）其存の場合に比べ てよくなかった・特に過塩素酸および硝酸酸性溶液から 法まったく沈殿せず, 塩酸および硫酸酸性の場合もチタ ン, タンタルは単独の場合よりも回収率が低下し, ス ズは塩酸酸性の場合まったく沈殿しなかった。なお鉄 （III）共存の場合は，金属イオン単独の場合や鉄（II） 共存の場合に比べ酸濃度が高いほうが回収率がよく，盐 酸，硫酸酸性とも約 $2 N$ が最も回収率が高かった。

（3）鉄の共沈量：鉄もフィチンにより一部沈殿する ので，次に溶液中の酸の種類および濃度と鉄 (II) の沈 殿量との関係，およびチタン（IV) またはニオブ (V) と共存する場合の鉄（II）の共沈量について調べた。そ の結果，溶液中鉄（II） $1 \mathrm{~g}$ からの沈殿量は, Fig. 3 に 示す上うに塩酸, 過塩素酸および硫酸いずれの酸性溶液 においても $10 \mathrm{mg}$ 以下であり，また酸の濃度が高くな るほど沈殿量は減少した. チタン (IV) $2 \mathrm{mg}$ または二 オブ (V) $2 \mathrm{mg}$ と鉄（II） $1 \mathrm{~g}$ が共存する場合の鉄の共 沈量は，Fig. 4 に示すように，いずれの場合も $3 \sim 8 \mathrm{mg}$ であり，鉄 (II) $1 \mathrm{~g}$ 単独の場合の沈殿量とほぼ同量で あったしたがって鉄（II）の状態でフィチンによる沈 

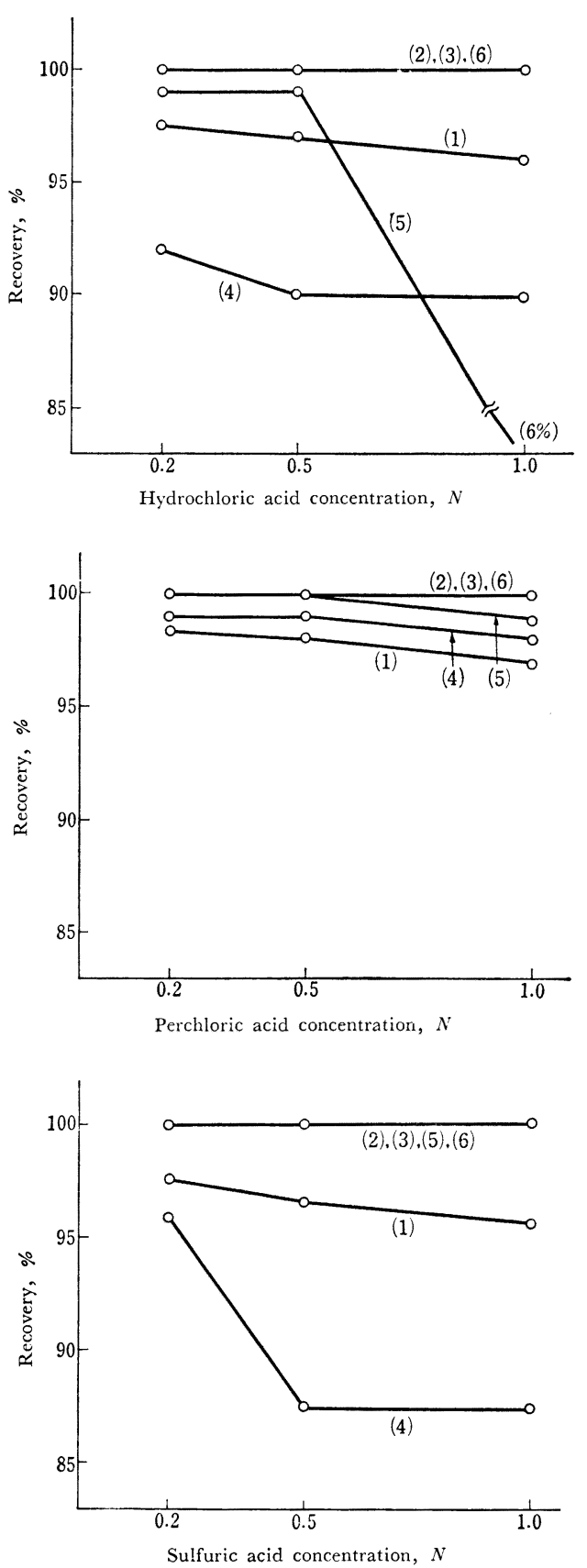

Fig. 2 Influence of ferrous ion on the precipitation of metal ions

$1.0 \mathrm{~g} \mathrm{Fe}$ (II) added in each sample solution; (1) Titanium; (2) Zirconium; (3) Niobium; (4) Tantalum; (5) Tin; (6) Thorium

殿分離を行なえば，試料量 $1 \mathrm{~g}$ の場合で鉄共沈量はほぼ $10 \mathrm{mg}$ 以下と考光られる。

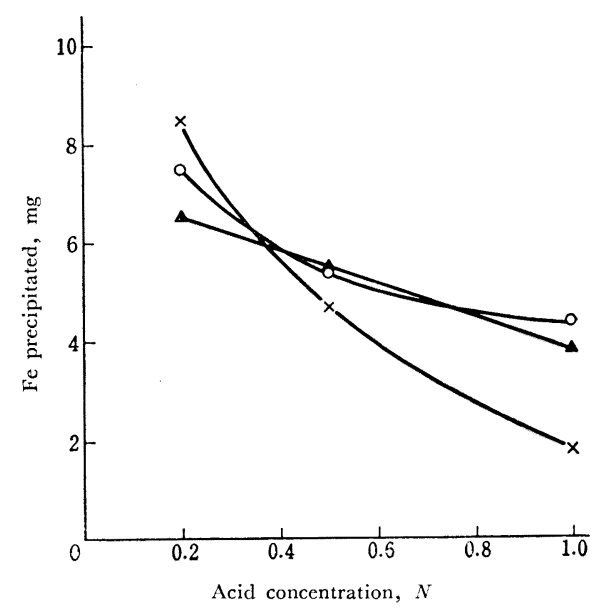

Fig. 3 Effect of concentration of hydrochloric or perchloric or sulfuric acid on the precipitation of iron(II) $\mathrm{Fe}$ (II) taken : $1.0 \mathrm{~g} ;-\mathbf{\Delta}-\mathrm{HCl}$; $-\mathrm{O}-\mathrm{HClO}_{4}$; $-\times-\mathrm{H}_{2} \mathrm{SO}_{4}$

3.2.3 フィチン溶液添加量の影響 以上:の实験結果 から鉄 (II) が共存する埸众，フィチン溶液 $10 \mathrm{ml}$ 空用 いればチタン (IV)，ジルコニウム (IV)，ニオブ (V)， タンタル (V)，スズ（IV）打よびトリウム (IV) の各 イオン注過㙁素酸酸性溶液少ら $100 \%$ 沈殿する。し灾し 鉄（III）方共存与ると间収染注 100\%に達しないこと がわかったが，鉄鋼分析においては鉄（II）溶液より当 鉄 (III) 溶液にしたほうが陚料の分解やその他一連の操 作が容易となる。そこで鉄 (III) が其存する埸会はフィ チン溶液添加量を增加すれ比回收率の向上が望まれるこ とが考元られたので，10４0 $\mathrm{ml}$ の範用にして各金属イ オンの回収率を調べた。

その結果, フィチン溶液の添加量を $40 \mathrm{ml}$ に増加して もチタン，ニオブおよびタンタルを完全に回収すること はできないこと，および鉄 (III) の其沈量が著しく増大 して分析に際しむしろ不利な絬果它与劣ることなどがう かった.

3.2.4 有機酸の影響 次にフィチンにより沈殿分離 する際の有機酸の影響它調べた。

その結果，Table II にホ寺ように，フィチンによる 沈殿生成時に $0.1 M$ のシュウ酸，クエン酸また酒石酸 を含さと沈殿の生成を妨害し，その影響はシュウ酸ぶ最 も大きく，ついで酒石酸打よびクエン酸の順であった。 この結果からシュウ酸, クエン陵打よび酒石酸でこれら の金属イオンをマスキングし，選択的にフィチンにより 沈殿分離することはできないことが打ふった。 

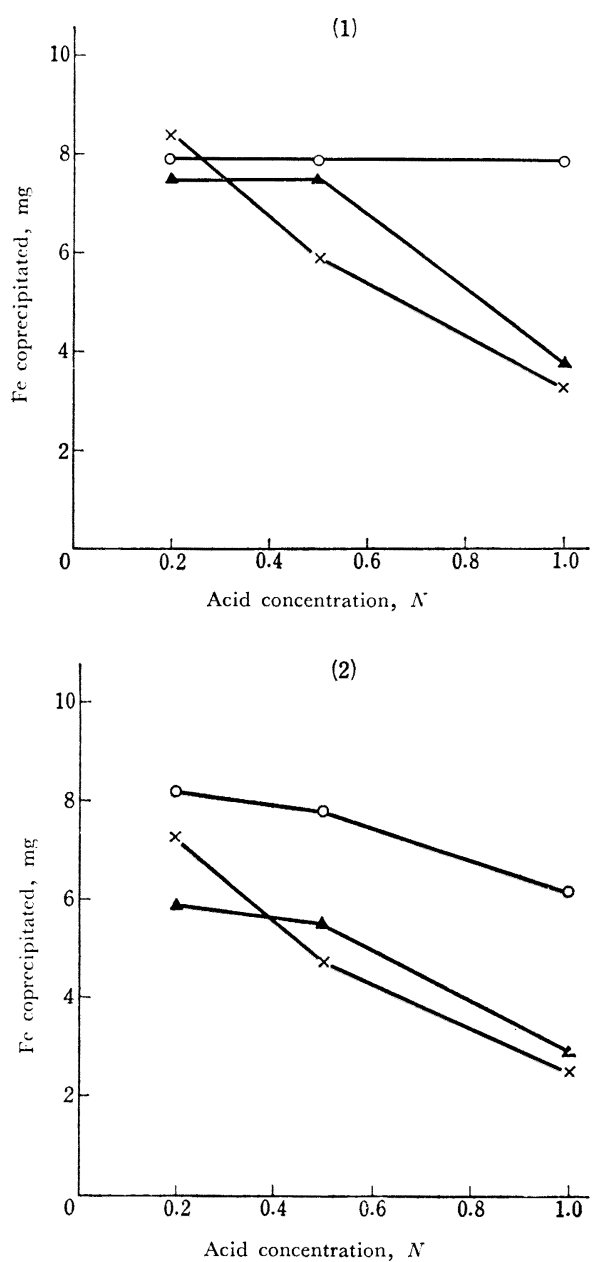

Fig. 4 Coprecipitation of iron(II) with titanium (IV) or niobium (V)

(1) Coprecipitation of iron(II) with titanium(IV); (2) Coprecipitation of iron(II) with niobium(V); Fe(II) taken : $1 \mathrm{~g}$; $\mathrm{Ti}(\mathrm{IV})$ or $\mathrm{Nb}(\mathrm{V})$ taken $: 2.0 \mathrm{mg}$; $-\Delta-\mathrm{HCl} ;-\mathrm{O}-\mathrm{HClO}_{4} ;-\times-\mathrm{H}_{2} \mathrm{SO}_{4}$

\section{3 沈殿の組成}

フィチンと金属イオンの沈殿組成を調ベる目的で，チ タン，ニオブォよびトリウムの 3 元素を選び，それぞれ 過塩素酸酸性溶液 $(0.5 N)$ からフィチンにより沈殿を 生成させ，その沈殿の元素分析兄行なった，その結果を

Table III に示守.

フィチン酸のカルシウム塩については

$\left.\mathrm{C}_{6} \mathrm{H}_{12} \mathrm{O}_{24} \mathrm{P}_{6} \mathrm{Ca}_{3} \cdot 3 \mathrm{H}_{2} \mathrm{O}_{2}\right)$

$\left.\mathrm{C}_{6} \mathrm{H}_{16} \mathrm{O}_{27} \mathrm{P}_{6} \mathrm{Ca}_{4} \cdot 12 \mathrm{H}_{2} \mathrm{O}^{3}\right)$

$\left.\mathrm{C}_{6} \mathrm{H}_{14} \mathrm{O}_{27} \mathrm{P}_{6} \mathrm{Ca}_{5}{ }^{3}\right)$
Table II Effects of organic acids on recoveries of titanium(IV), zirconium(IV), nio$\operatorname{bium}(\mathrm{V}), \operatorname{tantalum}(\mathrm{V})$ and $\operatorname{tin}(\mathrm{IV})$

\begin{tabular}{|c|c|c|c|c|}
\hline Ion & Org. acid & $\begin{array}{l}\text { Ion taken } \\
(\mathrm{mg})\end{array}$ & $\begin{array}{l}\text { Ion precipi- } \\
\text { tated }(\mathrm{mg})\end{array}$ & $\begin{array}{c}\text { Recovery } \\
(\%)\end{array}$ \\
\hline \multirow[t]{3}{*}{$\mathrm{Ti}(\mathrm{IV})$} & Oxalic acid & 2.00 & 1.78 & 89.0 \\
\hline & Citric " & " & 1.98 & 98.5 \\
\hline & Tartaric " & " & 2.05 & 102.5 \\
\hline \multirow[t]{3}{*}{$\operatorname{Zr}(I V)$} & Oxalic acid & 2.00 & 1.30 & 65.0 \\
\hline & Citric " & "I & 2.00 & 100.0 \\
\hline & Tartaric " & 11 & 1.48 & 74.0 \\
\hline \multirow[t]{3}{*}{$\mathrm{Nb}(\mathrm{V})$} & Oxalic acid & 2.00 & 0.013 & 0.63 \\
\hline & Citric " & "I & 2.00 & 100.0 \\
\hline & Tartaric " & " & 2.00 & 100.0 \\
\hline \multirow[t]{3}{*}{$\mathrm{Ta}(\mathrm{V})$} & Oxalic acid & 2.00 & 0.88 & 44.0 \\
\hline & Citric " & "I & 2.00 & 100.0 \\
\hline & Tartaric " & " & 2.00 & 100.0 \\
\hline \multirow[t]{3}{*}{$\operatorname{Sn}(I V)$} & Oxalic acid & 2.00 & 1.55 & 77.5 \\
\hline & Citric "I & "I & 1.90 & 95.0 \\
\hline & Tartaric " & " & 1.56 & 78.0 \\
\hline
\end{tabular}

Table III Elemental analysis of precipitates

\begin{tabular}{lccccc}
\hline \hline & $\begin{array}{c}\mathrm{C} \\
(\%)\end{array}$ & $\begin{array}{c}\mathrm{H} \\
(\%)\end{array}$ & $\begin{array}{c}\mathrm{O} \\
(\%)\end{array}$ & $\begin{array}{c}\mathrm{P} \\
(\%)\end{array}$ & $\begin{array}{c}\text { Metal } \\
(\%)\end{array}$ \\
\hline Phytin $\dagger$ & 7.81 & 3.18 & 55.21 & 16.5 & 17.3 \\
Ti ppt & 7.70 & 3.63 & 56.87 & 19.0 & 12.8 \\
Nb ppt & 6.30 & 3.41 & 58.39 & 15.5 & 16.4 \\
Th ppt & 7.38 & 2.41 & 39.81 & 17.5 & 32.9 \\
\hline
\end{tabular}

などが知られているが，著者らが実験に用いたフィチン 酸カルシウム（岸田化学製） は元素分析值より原子の比 率はほぼ $\mathrm{C}: \mathrm{H}: \mathrm{O}: \mathrm{P}: \mathrm{Ca}=6.5: 32: 35: 5.3: 4.3$ と なり，分子式は

$$
\begin{aligned}
& \mathrm{C}_{6} \mathrm{H}_{8} \mathrm{O}_{24} \mathrm{P}_{6} \mathrm{Ca}_{5} \cdot 12 \mathrm{H}_{2} \mathrm{O} \\
& \left(\begin{array}{r}
\text { 理論值 } \quad \mathrm{C}: 6.76 \%, \mathrm{H}: 3.02 \%, \mathrm{O}: 54.00 \%, \\
\mathrm{P}: 17.42 \%, \mathrm{Ca}: 18.79 \%
\end{array}\right) \\
& \text { または } \\
& \mathrm{C}_{6} \mathrm{H}_{10} \mathrm{O}_{24} \mathrm{P}_{6} \mathrm{Ca}_{4} \cdot 12 \mathrm{H}_{2} \mathrm{O} \\
& \left(\begin{array}{l}
\text { 理論值 } \quad \mathrm{C}: 7.01 \%, \mathrm{H}: 3.33 \%, \mathrm{O}: 56.00 \%, \\
\mathrm{P}: 18.07 \%, \mathrm{Ca}: 15.59 \%
\end{array}\right)
\end{aligned}
$$

か, あるい梳これらの混合物と考えられる. 元素分析值 のみから分子式を決河ることはできないが，チタン，二 オブおよびトリウムの沈殿について分子式を推定してみ ると，それぞれ次のような分子式が考えられ，いずれも 不溶性のフィチン酸の金属塩として沈殿するものと考元 られる。

$$
\text { チタン } \mathrm{C}_{6} \mathrm{H}_{6} \mathrm{O}_{24} \mathrm{P}_{6} \mathrm{Ti}_{3} \cdot 12 \mathrm{H}_{2} \mathrm{O}
$$




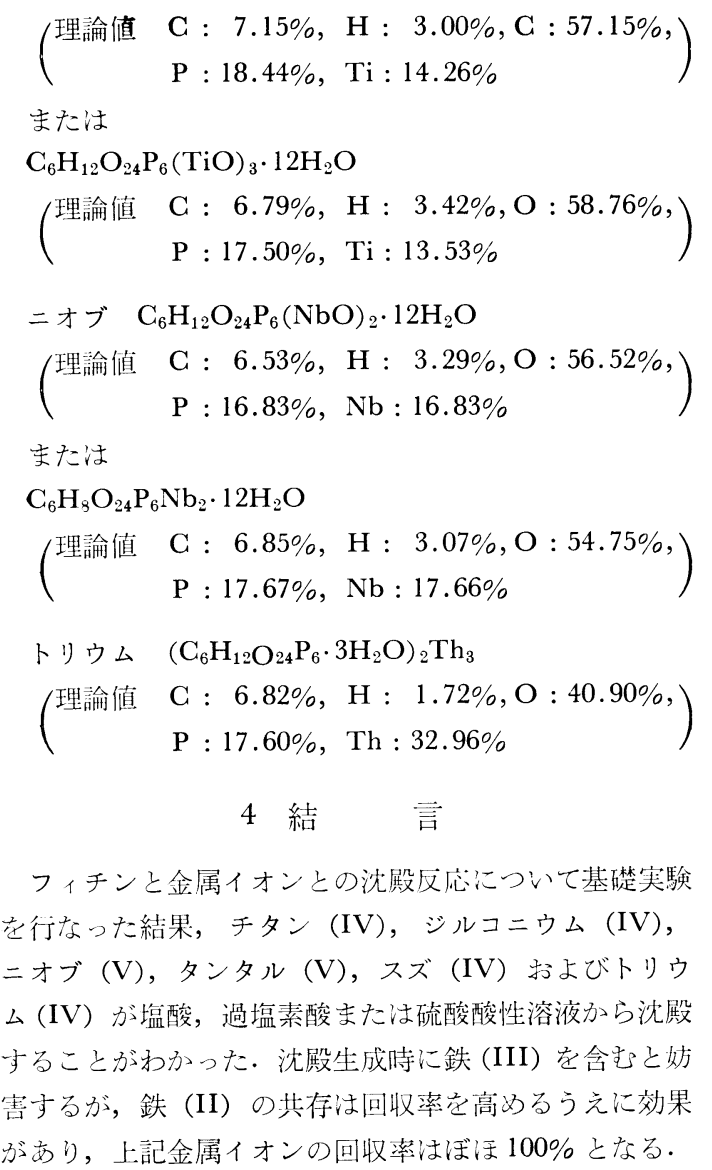

本法は操作が簡単でしかも鉄の其沈星が微星なので，適 当な定量法と組み合わせれ就鉄鋼中のこ扎ら成分の分析 法としてじゅうぶえ利用価估があるもの上考える。

（昭和 41 年 10 月 17 日，本会旌15年会に打いて発表）

\section{交献}

1) E. B. Sandell : "Colorimetric Determination of Traces of Metals", 3rd Ed., p. 793 (1959), (Interscience Publishers Inc., New York).

2) Deutschen Chemischen Geselshaft : Beilsteins Handbuch der Organischen Chemie", 4te Aufl., Band 6, S. 1197 (1923).

3）化学大辞典編集委員会緗: “化学大㱠典”, 7 卷, p. 646 (1961)，（共立出版）

Isolation of titanium(IV), zirconium (IV), $\operatorname{niobium}(\mathrm{V}), \operatorname{tantalum}(\mathrm{V}), \operatorname{tin}(\mathrm{IV})$ and thorium(IV) by precipitation with phytin. Eiji Futamura and Hiromu Kuroki(Technical Research Institute, Yawata Iron and Steel Co., Ltd., Yawata-ku, Kitakyushu-shi, Fukuoka-ken)

It has been found that phytin reacts with titanium(IV), zirconium(IV), niobium $(\mathrm{V})$, tantalum(V), tin(IV), and thorium(IV) to give white precipitates from boiling acidic solutions. The reaction is more complete in a perchloric acid solution than in a hydrochloric or sulfuric acid solution, and is 100 per cent or nearly 100 per cent quantitative in the presence of ferrous ion. The amount of coprecipitated iron is small.

This reaction can possibly be applied to the isolation of above mentioned elements in the analysis of iron and steel.

(Received Oct. 12, 1967) 